\title{
Fresh Air and Sufficient Oxygen Content in it Contribute to the Birth of a Healthy and Intelligent Child
}

\author{
Aleksandr L Urakov ${ }^{1 *}$ and Natalya A Urakova ${ }^{2}$ \\ ${ }^{1}$ Professor, Head of the Department of General and Clinical Pharmacology, Izhevsk \\ State Medical Academy and Leader Researcher, Institute of Mechanics, Udmurt \\ Federal Research Center, Ural branch of the Russian Academy of Sciences, Izhevsk, \\ Russia \\ ${ }^{2}$ Associate Professor of the Department of Obstetrics and Gynecology, Izhevsk State \\ Medical Academy, Izhevsk, Russia \\ *Corresponding Author: Aleksandr L Urakov, Professor, Head of the Department of \\ General and Clinical Pharmacology, Izhevsk State Medical Academy, Izhevsk, Russia.
}

Every woman since childhood dreams of successfully getting married and becoming a happy mother. Every woman with trepidation and with great responsibility prepares for the upcoming pregnancy, because she realizes that a healthy lifestyle largely determines the normal development of her fetus. It is no secret that after the onset of pregnancy, it is the pregnant woman who is responsible for the birth of a healthy, intelligent and capable child. Of course, a lot of things are determined by the appropriate "necessary" heredity and the "necessary" genes received by the fetus from the parents. However, it is not only this that determines the birth of a healthy, intelligent and capable child. Very much depends on the conditions under which the embryo originated, formed and developed, as well as on the conditions in which the fetus grew inside the mother's womb and in what conditions it was born.

The role of parents as sources of genes is very high for their child's belonging to a certain race and/or nationality and for forming it with such biometric, anatomical, physical, biochemical and physiological parameters of the body that form the distinctive features of representatives of this race and/or nationality. Therefore, hardly anyone will doubt that a child of Russian parents inherits characteristic Slavic traits, a child of Japanese parents inherits Japanese traits, and a child of pygmy parents inherits traits typical of the pygmy tribe. Moreover, a mother can change the hereditary traits in her children only before their conception. To do this, need to change their fathers. The fact is that after the conception of a child, these signs cannot be changed, even if the mother is replaced (for example, with a surrogate mother). In this regard, hereditary characteristics practically do not depend on the characteristics of the course of pregnancy and childbirth, and therefore on the desire and behavior of the pregnant woman and the competence of obstetricians and gynecologists.

Another thing is the state of the environment, the quality of water, food and air that interact with the woman's body and penetrate into it, as well as the lifestyle and state of her health, both before pregnancy and during pregnancy and childbirth. Each of these factors and all of them together greatly affect the quality of development of the embryo, the quality of the formation of the fetus from it, their health and vitality inside the mother's womb and after birth. Moreover, the completeness of the disclosure of potential mental abilities in a living born child in the future depends on them. There is no doubt that the optimal values of these interaction factors contribute to the optimal development of the embryo and fetus and the preservation of physical health and spiritual abilities in the born child. In turn, the deviation of the values of these factors from the norm worsens the health and mental abilities of the child in the future. In addition, the harmful effect of "abnormal" factors on the fetus is greater, the more their appearance corresponds to the period of greatest vulnerability of certain processes of embryo development and fetal formation during pregnancy and childbirth. 
As an example, consider how the oxygen content in the inhaled air and in the blood of a pregnant woman affects the viability and basic parameters of fetal development, as well as the physical and mental abilities of the born child in the future. Let's start with a reminder that at the beginning of its development, the human embryo and fetus resemble a fish first, and then an amphibian animal that swims in water and consumes a minimum amount of oxygen. In fact, for the entire first half of pregnancy, namely, until the 20th week of pregnancy, the viability and development of the fetus inside the uterus are much less dependent on oxygen than the viability and physical and mental performance of its mother. In this regard, in the first 20 weeks of pregnancy, the body of a pregnant woman is much more sensitive and at the same time much more vulnerable to a lack of oxygen (to hypoxia) than the body of her fetus. The consequence of this is that the degree of oxygen deficiency (hypoxia), which is deadly for a pregnant woman, is not fatal for her fetus. That is why during this period of pregnancy, the low level of oxygen, which is regarded by the body of a pregnant woman as hypoxia, is evaluated by the body of her fetus as quite normal (sufficient for life and development). In addition, in case of accidental hypoxia, the body of a pregnant woman immediately increases the level of oxygen in the body to the level normal for a woman. Thanks to this, the body of a living pregnant woman automatically eliminates the deadly level of hypoxia for the fetus inside her uterus. That is why in the first half of pregnancy, the mother's body supplies the embryo, and then the fetus with a sufficient amount of oxygen. Therefore, during this period of pregnancy, intrauterine fetal hypoxia is a low-probability threat factor for its development.

Fresh air and sufficient oxygen content begin to become more important for the pregnant woman and her fetus in the second half of pregnancy. The fact is that during this period, the fetus begins to rapidly increase the size of the head and the mass of the brain, since during this period, the fetus most intensively forms the brain. At the same time, it is the brain cells that are the leaders in the intensity of oxygen exchange in the fetus and it is the cells of the cerebral cortex that consume the largest part of the oxygen entering the fetus from the mother's body. Since the state of the cells of the cerebral cortex is responsible for the mental abilities of the child in the future, a good supply of oxygen to the fetus is the key to the birth of a child with a good cerebral cortex and with good mental abilities in the future.
So, from the middle of pregnancy, the fetus begins an intensive development of the brain, which increases the fetus ' need for oxygen. At the same time, with an increase in the duration of pregnancy, not only the mass of the brain increases, but also the mass of the entire body of the fetus, which also needs oxygen. Therefore, in the second half of pregnancy, the fetus ' need for oxygen is constantly increasing. At the same time, all organs and tissues of the fetus, except for its brain, can remain viable without oxygen for a sufficiently long period of time, namely, several tens of minutes or even more than this. Unfortunately, the fetal brain can only maintain its viability without oxygen for a few minutes.

Therefore, the presence of oxygen in the brain of the fetus should be continuous, since oxygen is necessary not only for the metabolism in the cells of the cerebral cortex, that is, their vital activity and development, but also for the preservation of their life. Therefore, even a short-term lack of oxygen (temporary intrauterine hypoxia) becomes a factor that threatens not only the mental abilities of the fetus, but also its life in the second half of pregnancy.

Therefore, starting from half of pregnancy, the presence of oxygen in the fetal brain should be continuous, since oxygen is necessary not only for the metabolism of the cells of the cerebral cortex, that is, their vital activity and development, but also for the preservation of their life. The fact is that stopping the delivery of oxygen to the fetal cortex can cause the death of cortical cells in a few minutes, and sometimes in a few tens of seconds. Therefore, in the second half of pregnancy, lack of oxygen (intrauterine hypoxia) becomes the most likely and disastrous factor for fetal cortex cells than before this term of pregnancy. At the same time, as the duration of pregnancy increases, the destructive effect of hypoxia increases.

It should be noted that by the middle of pregnancy, the lungs of the fetus are formed so that they are able to participate in the gas exchange of the fetus in the event of its birth, that is, in the environment of air. However, in a situation where the fetus is inside the uterus, there is no air with oxygen around the fetus. Moreover, the fetus is completely surrounded by amniotic fluid, in which there is no oxygen. Therefore, inside the mother's womb, the fetus does not have any oxygen gas around it. In this regard, in a critical situation, the use of this liquid by the fetus by swallowing and/or choking it does not increase the delivery of oxygen to the fetal brain. But for 
survival in the absence of oxygen, the fetus has adaptive reserves inside its body. True, these reserves allow him to keep alive in the cells of the cortex of his brain for no more than a few minutes of hypoxia.

What does the fetus do after all the reserves of its adaptation to hypoxia are exhausted? It turns out that in such a critical situation, the fetus has no choice but to signal its mother about its plight and "ask" her for more oxygen. Since there is no air in the fetus " lungs inside the uterus, it cannot scream. But the fetus can kick with its feet and hit the wall of the uterus with its hands! That's what he does. The fact is that normally (at normal oxygen levels), the fetus usually sleeps and does not make sudden movements with its limbs and does not kick. However, when the oxygen supply stops, the fetus remains stationary for a while to conserve oxygen. The duration of immobility of the fetus is greater, the more it has reserves of adaptation to hypoxia. But after the full exhaustion of the reserve, the fetus immediately wakes up and begins to twitch and abruptly straighten its arms and legs, hitting them against the wall of the uterus with great force. A pregnant woman intuitively "waits" for this signal, so she immediately feels it and begins to think about what is needed for the fetus inside her uterus.

For a long time, people did not fully understand the meaning of such kicks, which the fetus produces in the wall of the uterus in a pregnant woman. Now we know that the fetus knocks when its serene sleep is interrupted due to the fact that the fetus is missing something. The most important element of supply is the supply of oxygen to it. Therefore, the first thing a pregnant woman should do in such a situation is to increase her breathing until the appearance of dizziness in her head. At the same time, you need to increase the access of fresh air or go out to fresh air. To do this, open the windows and exterior doors, but it is best to leave the room outside. The fact is that the oxygen content in the indoor air can be reduced and make up $80 \%$ of its amount in the outdoor air. At the same time, it should be remembered that the oxygen content in the air decreases on hot days and increases on cool days; the oxygen content in the air decreases indoors the more people and/ or animals are in it; the oxygen content in the air decreases when climbing up. Therefore, the air on the high floors of buildings contains less oxygen than the air on the first floors. In addition, the air in the central part of large cities contains less oxygen than the air on its outskirts and around it.
In our opinion, the presented idea of the importance of oxygen in the development of the fetus and especially the cells of the cortex of its brain in the second half of pregnancy allows us to explain the benefits of fresh air and sufficient oxygen content in it and how the continuous supply of oxygen to the fetus contributes to the birth of a healthy and intelligent child.

In conclusion, we offer all pregnant women a simple test for the resistance of their fetus to hypoxia, which they can apply themselves at home. To do this, you need to hold your breath for 25 to 30 seconds to check whether or not their fetus will start kicking at this time. In a situation where the fetus does not start kicking during apnea, this is very good. So everything is normal: the fetus is well supplied with oxygen and has a good reserve of adaptation to intrauterine hypoxia. In a situation where the fetus begins to kick at the very beginning of apnea, you need to consult a doctor for an examination in order to find out the reason for the lack of adaptation of the fetus to hypoxia.

We wish all pregnant women in the second half of pregnancy to constantly breathe fresh air, or air with a rich oxygen content, in order to create continuous "oxygen" conditions for the beautiful development of their fetuses, so that they do not kick during apnea and are born pink with maximum mental abilities.

\section{Assets from publication with us}

- Prompt Acknowledgement after receiving the article

- Thorough Double blinded peer review

- Rapid Publication

- Issue of Publication Certificate

- High visibility of your Published work

Website: $\underline{w w w . a c t a s c i e n t i f i c . c o m / ~}$

Submit Article: www.actascientific.com/submission.php

Email us: editor@actascientific.com

Contact us: +919182824667 